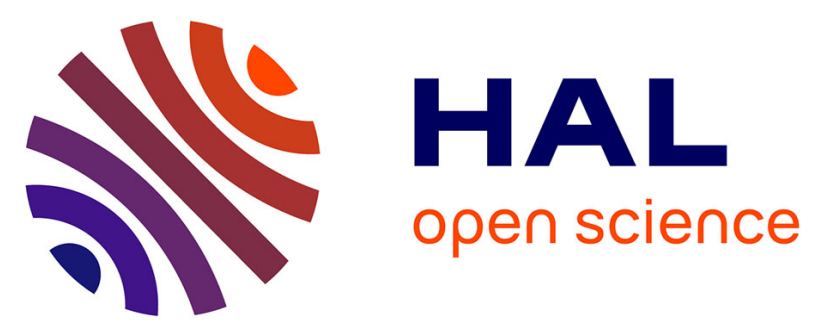

\title{
Plasma Treatments and Biomass Gasification
}

Jocelyn Luche, Quentin Falcoz, Thierry Bastien, Jean Philippe Leininger, Khadija Arabi, Olivier Aubry, Ahmed Khacef, Jean Marie Cormier, Jacques Lédé

\section{- To cite this version:}

Jocelyn Luche, Quentin Falcoz, Thierry Bastien, Jean Philippe Leininger, Khadija Arabi, et al.. Plasma Treatments and Biomass Gasification. IOP Conference Series: Materials Science and Engineering, 2012, 29, pp.1-10. 10.1088/1757-899X/29/1/012011 . hal-00679990

\section{HAL Id: hal-00679990 https://hal.science/hal-00679990}

Submitted on 16 Mar 2012

HAL is a multi-disciplinary open access archive for the deposit and dissemination of scientific research documents, whether they are published or not. The documents may come from teaching and research institutions in France or abroad, or from public or private research centers.
L'archive ouverte pluridisciplinaire HAL, est destinée au dépôt et à la diffusion de documents scientifiques de niveau recherche, publiés ou non, émanant des établissements d'enseignement et de recherche français ou étrangers, des laboratoires publics ou privés. 
Plasma Treatments and Biomass Gasification

This article has been downloaded from IOPscience. Please scroll down to see the full text article.

2012 IOP Conf. Ser.: Mater. Sci. Eng. 29012011

(http://iopscience.iop.org/1757-899X/29/1/012011)

View the table of contents for this issue, or go to the journal homepage for more

Download details:

IP Address: 193.49.77.4

The article was downloaded on 28/02/2012 at 10:45

Please note that terms and conditions apply. 


\title{
Plasma Treatments and Biomass Gasification
}

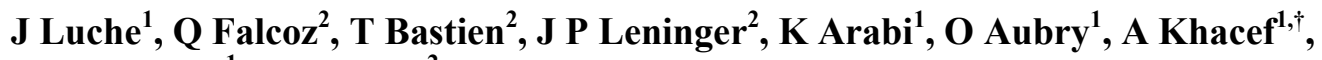 \\ $\mathbf{J}$ M Cormier ${ }^{1}$ and $\mathbf{J}$ Lédé $^{2}$ \\ ${ }^{1}$ GREMI, CNRS-Université d'Orléans, 14 Rue d'Issoudun, BP 6744, 45067 Orléans, \\ France \\ ${ }^{2}$ LRGP, Université de Nancy, 1 Rue Grandville, BP 20451, 54001 Nancy, France, \\ E-mail: ahmed.khacef@univ-orleans.fr
}

\begin{abstract}
Exploitation of forest resources for energy production includes various methods of biomass processing. Gasification is one of the ways to recover energy from biomass. Syngas produced from biomass can be used to power internal combustion engines or, after purification, to supply fuel cells. Recent studies have shown the potential to improve conventional biomass processing by coupling a plasma reactor to a pyrolysis cyclone reactor. The role of the plasma is twofold: it acts as a purification stage by reducing production of tars and aerosols, and simultaneously produces a rich hydrogen syngas. In a first part of the paper we present results obtained from plasma treatment of pyrolysis oils. The outlet gas composition is given for various types of oils obtained at different experimental conditions with a pyrolysis reactor. Given the complexity of the mixtures from processing of biomass, we present a study with methanol considered as a model molecule. This experimental method allows a first modeling approach based on a combustion kinetic model suitable to validate the coupling of plasma with conventional biomass process. The second part of the paper is summarizing results obtained through a plasma-pyrolysis reactor arrangement. The goal is to show the feasibility of this plasma-pyrolysis coupling and emphasize more fundamental studies to understand the role of the plasma in the biomass treatment processes.
\end{abstract}

\section{Introduction}

Biomass gasification processes produce synthetic gas (syngas) that can be used for further catalytic synthesis of Fischer-Tropsch fuels, SNG fuels, $\mathrm{H}_{2}$ or for the direct production of heat and electricity. For these applications, high quality of syngas is required, including very low tar contents. Among the conventional gas purification technologies, plasmas offer an interesting alternative, as it is well known that plasmas can efficiently convert hydrocarbons into syngas.

Started at the end of 2006 and achieved in 2010, the Pyroplasm ANR French project [1] had combined a high temperature cyclone reactor and a plasma reactor to quantitatively study the abatement efficiency of condensable vapours produced by biomass pyro-gasification.

The cyclone reactor is well known for its gas-solid separation properties, but it can be also considered as a high temperature reactor for solid reactions. Fast heating followed by thermo-chemical reactions occur along the heated walls of the cyclone. The solid residues are then automatically separated at the bottom of the reactor and the fluid products leave the cyclone at its top [2].

\footnotetext{
${ }^{\dagger}$ To whom any correspondence should be addressed
} 
Previous studies have shown the potential of using a cyclone for biomass pyro-gasification. Depending on the operating conditions, the fractions of oils and gases produced can be very different [3-6]. As example, biomass produces $75 \%$ of oils at $880 \mathrm{~K}$ (reactor wall temperature) and $80 \%$ of gases at $1220 \mathrm{~K}$. Such a multifunctional reactor is thus very interesting to carry out either gas production or bio-oil production.

Tar reduction or destruction during biomass gasification is a most of concern topic for current scientific research [6]. A lot of different technologies have been already studied: mechanism method such as cyclone, filters, electrostatic precipitator, scrubbers; catalytic or thermal cracking or plasma methods.

Plasmas offer a lot of possibilities for waste treatment and valorisation, bio fuel production, pollution control or gas treatment. In this work, the reactor used for pyro-gasification and the plasma reactor are separated and placed in series in order to study the plasma effect on tar removal.

In the first part of this paper, we present results obtained from plasma treatment of bio-oils. These oils are produced by using the cyclone-pyrolysis arrangement. The outlet gas composition is given for various types of oils obtained at various wall temperatures of the cyclone-reactor. Results obtained are quite difficult to discuss because the nature and the composition of oils are unknown. Complementary experiments were performed by using methanol considered as a model molecule for which a kinetic combustion mechanism is available. The discussion of the effects produced by the plasma can then be opened.

The second part summarizes results obtained with the hybrid plasma-pyrolysis system [8].

\section{Bio-oils and methanol steam-reforming}

One way of storing the biomass energy is to produce oils from the biomass. Oils have higher energy density than natural biomass. The implementation of a plasma process can be used for the bio-oils cracking and then produce hydrogen rich gas mixture.

This part of the paper presents results obtained from plasma treatment of bio-oils and methanol. These oils are produced by using a cyclone-pyrolysis arrangement [2-6].

\subsection{Experimental techniques}

The studies are performed using a simplified plasma reactor called Statarc [9] generating a more stable arc than the plasma torch used in Pyroplasm project. Laboratory scale experiments (figure 1) were carried out with liquid mixtures injected with a syringe pump in the Statarc reactor at atmospheric pressure and low temperature.

The low current plasma arc reactor includes two graphite electrodes in a quartz tube $(400 \mathrm{~mm}$ length and $30 \mathrm{~mm}$ inner diameter). The electrodes gap is adjustable from 1 to $2 \mathrm{~cm}$.
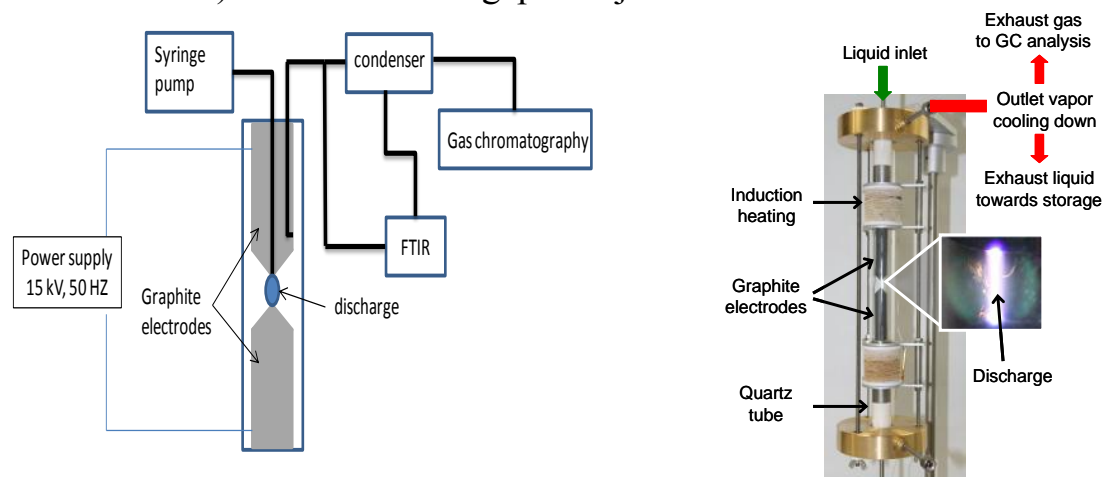

Figure 1. Simplified diagram of the experimental set-up and a photography of the Statarc reactor. 
The reactor is powered by a $50 \mathrm{~Hz}$ high voltage transformer with leakage flux. The current and voltage are measured using specific probes. The signals are recorded on a digital oscilloscope as shown in figure 2. From the current and voltage data, the power can be calculated.

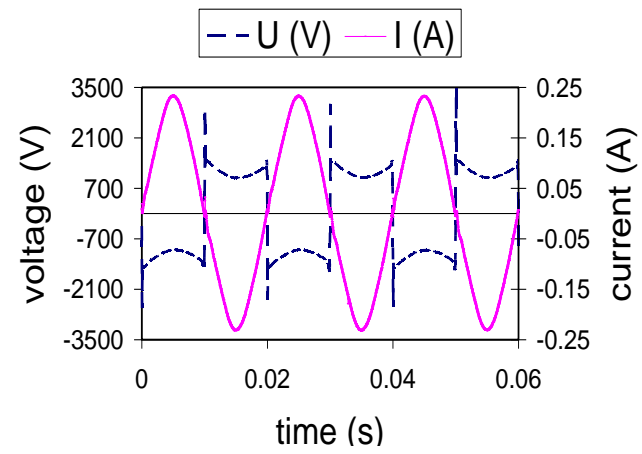

Figure 2. Voltage and current waveforms: liquid volume methanol to water ratio of 0.23 .

Chemical analyses of dry exhaust gas are performed to measure species concentrations. The outlet gas is condensed using a cryogenic trap $\left(-20^{\circ} \mathrm{C}\right)$ and analyzed using a gas phase chromatography analyzer (GC-Varian CP 3800) and Fourier transform infrared spectrometer (FTIR). FTIR analyses without cryogenic device showed that the $\mathrm{CO}$ and $\mathrm{CO}_{2}$ are not trapped. So, the analyses carried out in dry gases are representative of plasma-treatment.

\subsection{Results}

2.2.1. Steam reforming of Bio-oils. Experiments are achieved with light or heavy bio-oils (HPL and $\mathrm{HPH}$, respectively or Heavy tars and Light tars respectively) produced from fast pyrolysis process reactor (Pyroplasm facility) at different wall temperature of the cyclone reactor $(900,1000$, and 1100 $\mathrm{K})$. Characteristics of bio-oils used in this study are given in table 1 .

Table 1. Bio-oils characteristics [5]

\begin{tabular}{|r|c|c|c|}
\cline { 3 - 4 } \multicolumn{1}{c|}{} & $\mathrm{T}(\mathrm{K})$ & $\begin{array}{c}\text { Heavy bio-oil } \\
(\mathrm{HPH})\end{array}$ & $\begin{array}{c}\text { Light bio-oil } \\
(\mathrm{HPL})\end{array}$ \\
\hline Viscosity (Pa.s) & \multirow{2}{*}{295} & $\geq 0.15$ & $\leq 0.01$ \\
\cline { 1 - 2 } \cline { 3 - 4 } Density $(\mathrm{g} / \mathrm{mL})$ & & $\sim 1.20$ & $\sim 1.05$ \\
\hline \multirow{2}{*}{ Molar elementary composition } & 900 & $\mathrm{CH}_{1.55} \mathrm{O}_{0.67}$ & $\mathrm{CH}_{5.06} \mathrm{O}_{3.03}$ \\
\cline { 3 - 4 } & 1000 & $\mathrm{CH}_{1.01} \mathrm{O}_{0.23}$ & $\mathrm{CH}_{1.49} \mathrm{O}_{0.20}$ \\
\hline
\end{tabular}

Dry output gas is analysed and $\mathrm{H}_{2}, \mathrm{O}_{2}, \mathrm{~N}_{2}, \mathrm{CO}, \mathrm{CO}_{2}, \mathrm{CH}_{4}, \mathrm{C}_{2} \mathrm{H}_{2}, \mathrm{C}_{2} \mathrm{H}_{4}$ and $\mathrm{C}_{2} \mathrm{H}_{6}$ species are quantified. The heaviest species are mainly $\mathrm{CH}_{4}$ and $\mathrm{C}_{2}$-hydrocarbons with mole concentrations ranged from $0.3 \%$ to $4 \%$. Other species are negligible, so we only present the evolution of main produced species: $\mathrm{H}_{2}, \mathrm{CO}$, and $\mathrm{CO}_{2}$.

In figure 3, exhaust gas mole fractions and $\mathrm{H}_{2} / \mathrm{CO}$ ratio are displayed as a function of the wall pyrolysis reactor temperature used to obtain the light and heavy bio-oils. These results suggest that bio-oil reforming by non-thermal plasma is strongly influenced by four parameters:

- wall pyrolysis reactor temperature,

- bio-oil nature, 
- bio-oil diluted or not with water,

- bio-oil flow rate.

Conversion rates of light and heavy bio-oils into syngas are $20-25 \%$ (wt) and 10-15\% (wt), respectively. After the plasma treatment, significant $\mathrm{H}_{2} / \mathrm{CO}$ concentration ratios are obtained in experiments using bio-oils produced at low temperature $(900 \mathrm{~K})$ and bio-oils diluted in water. In addition, higher $\mathrm{H}_{2} / \mathrm{CO}$ ratios are obtained from light bio-oil plasma treatment compared to those obtained with heavy bio-oil. No significant influence of bio-oil flow rate variation is observed on syngas and $\mathrm{CO}_{2}$ mole fractions.

From these results, two main comments can be done: The first one concern the comparison between the composition of a gas produced by pyro-gasification and a gas obtained from plasma biooil steam reforming. The second one concerns the comparison between the experimental and theoretical compositions.
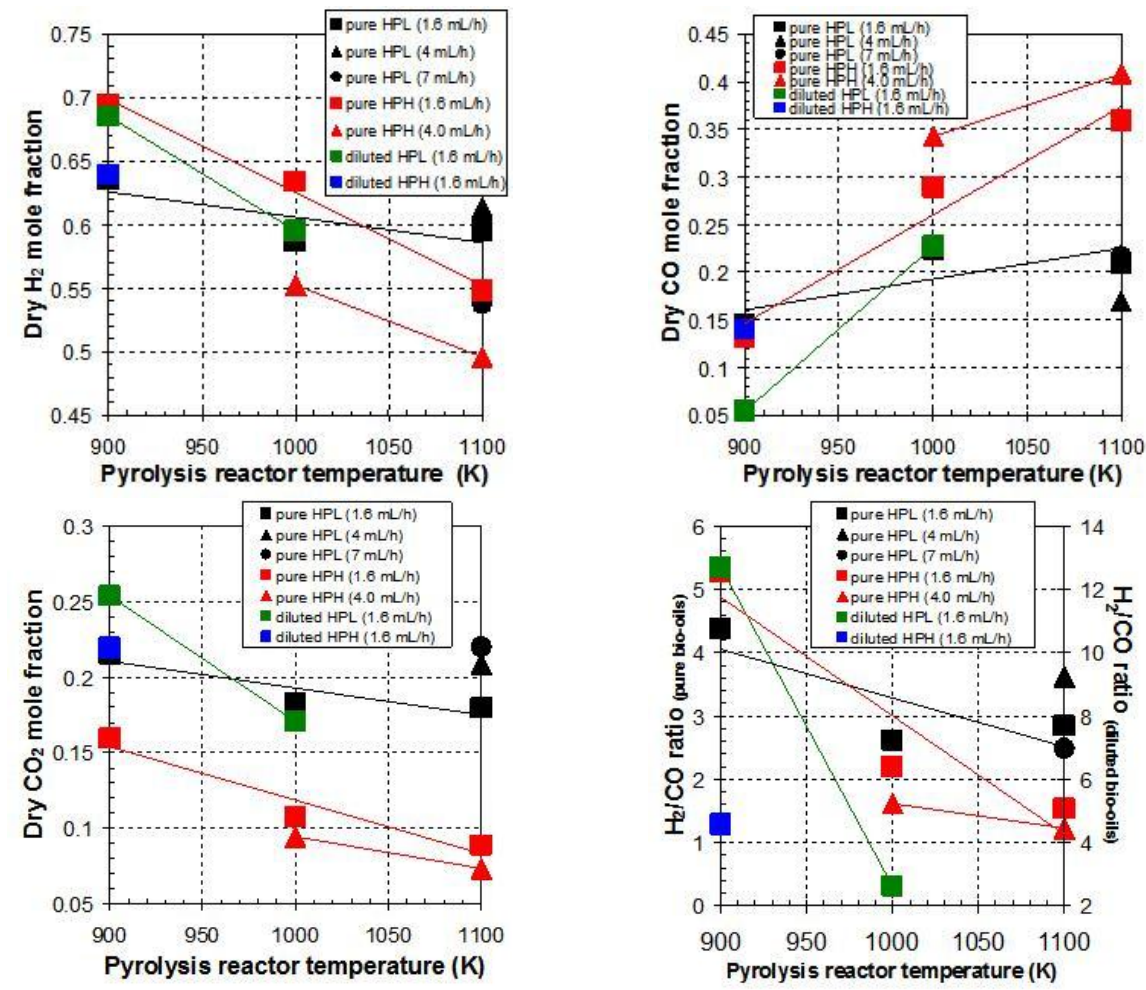

Figure 3. Plasma treatment results: $\mathrm{H}_{2}, \mathrm{CO}, \mathrm{CO}_{2}$ mole fractions and $\mathrm{H}_{2}$ to $\mathrm{CO}$ ratio as a function of the wall pyrolysis reactor temperature for different bio-oils at different flow rates.

2.2.2. Comparison between the composition of a gas from pyro-gasification and from plasma bio-oil steam reforming. The results obtained using the pyro-gasification facility [8] show that the compositions of the output gas mixtures are generally close to the following composition: $18 \% \mathrm{H}_{2}$, $63 \% \mathrm{CO}, 12.5 \% \mathrm{CO}_{2}, 2.5 \% \mathrm{CH}_{4}$, and $1 \% \mathrm{C}_{2}-\mathrm{C}_{3}$ species. The synthesis gas obtained from a pyrogasification includes many more carbon monoxide than hydrogen $\left(\mathrm{H}_{2} / \mathrm{CO} \# 0.3\right)$.

In experiments where the synthetic gas is obtained by plasma reforming of bio-oil, the $\mathrm{H}_{2} / \mathrm{CO}$ ratio is higher, between 2 and 9. Thus, high hydrogen enrichment can be obtained using plasma steam reforming.

Although the gas mixtures at the reactor outlet include small amounts of methane and heavier hydrocarbons, $\mathrm{CO}$ and $\mathrm{H}_{2}$ remain the most energizing components. Therefore the ratio of $\mathrm{H}_{2} / \mathrm{CO}$ is a significant parameter of the process. 
2.2.3. Comparison between experimental and theoretical compositions. Biomass composition can be described by the following overall formula: $\mathrm{C}_{6} \mathrm{H}_{9} \mathrm{O}_{4}$. Consider a typical steam reforming reaction derived from reaction:

$$
\mathrm{C}_{6} \mathrm{H}_{9} \mathrm{O}_{4}(\mathrm{~s})+5 \mathrm{H}_{2} \mathrm{O}(\mathrm{g}) \rightarrow 3 \mathrm{CO}(\mathrm{g})+3 \mathrm{CO}_{2}(\mathrm{~g})+9.5 \mathrm{H}_{2}(\mathrm{~g})
$$

From this overall reaction, $\mathrm{CO}$ and $\mathrm{CO}_{2}$ concentrations in gas phase are equal and the theoretical corresponding value of $\mathrm{H}_{2} / \mathrm{CO}$ ratio is about 3.16. Reaction (1) is not a general reaction; it is merely useful to give the order of magnitude of the main products. In the general case, the $\mathrm{CO}$ and $\mathrm{CO}_{2}$ are produced at different values, so, general equation must take into account the water gas shift reaction (WGSR, reaction (2)):

$$
\mathrm{CO}(\mathrm{g})+\mathrm{H}_{2} \mathrm{O}(\mathrm{g}) \rightarrow \mathrm{CO}_{2}(\mathrm{~g})+\mathrm{H}_{2}(\mathrm{~g})
$$

As an example, in case of following reaction the $\mathrm{H}_{2} / \mathrm{CO}$ value is 5.25

$$
3 \mathrm{CO}(\mathrm{g})+3 \mathrm{CO}_{2}(\mathrm{~g})+9.5 \mathrm{H}_{2}(\mathrm{~g})+\mathrm{H}_{2} \mathrm{O}(\mathrm{g}) \rightarrow 2 \mathrm{CO}(\mathrm{g})+4 \mathrm{CO}_{2}(\mathrm{~g})+10.5 \mathrm{H}_{2}(\mathrm{~g})
$$

It can be concluded that the results obtained by plasma steam reforming are consistent with a simplified analysis based on an overall chemical equations.

$\mathrm{CO}$ and $\mathrm{CO}_{2}$ production are not produced from the solid carbon due to electrodes ablation. The carbon consumption has been estimated to be in the range of $1.7 \times 10^{-7} \mathrm{~mol}^{-\mathrm{min}^{-1}}$, which means that ablation does not contribute to $\mathrm{CO}_{2}$ or $\mathrm{CO}$ production.

2.2.4. Methanol steam reforming. The above results show the interest to access to a more detailed understanding of the mechanisms involved. We have therefore chosen a molecule that can be considered a model with known kinetics of combustion. This molecule is methanol. Steam reforming using non thermal plasma processes was presented previously [9]. Some authors have also performed plasma reactor experiments in water, alcohol, and hydrocarbons for $\mathrm{H}_{2}$ production with high $\mathrm{H}_{2}$ yield at limited energy cost $[10,11]$.

Some results obtained from Methanol are plotted on figure 4. This graph reports results obtained at a constant injection flow rate for various compositions of the inlet mixture.

The amount of $\mathrm{H}_{2}$ decreases slightly and the amounts of $\mathrm{CO}$ and $\mathrm{CO}_{2}$ are most sensitive to the initial composition. It is quite difficult to discuss such results; therefore, we propose a simplified analysis based on a combustion model.

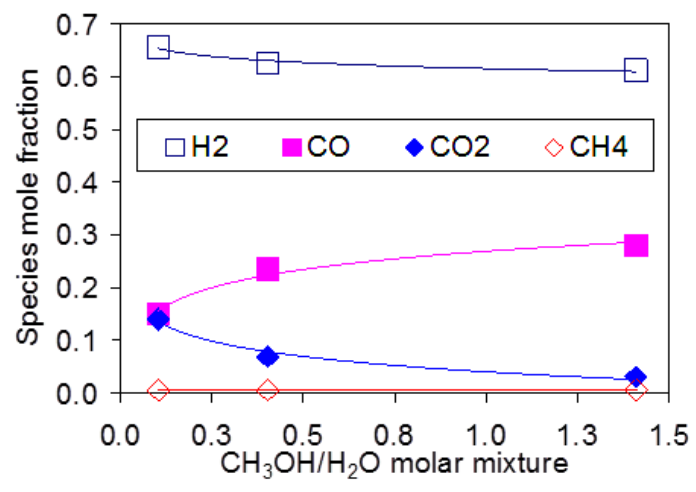

Figure 4. $\mathrm{H}_{2}, \mathrm{CO}, \mathrm{CO}_{2}$ and $\mathrm{CH}_{4}$ mole fraction as a function of inlet liquid molar Methanol/water ratio (total liquid flow rate $=1.26 \mathrm{sccm}$ ).

2.2.5. Modeling and experiment-modeling comparison. Results presented above are obtained from a reactor in which a stationary discharge is produced. Modeling of the discharge involves understanding of various and complex physico-chemical phenomena, especially non thermal discharge modeling, 
hydrodynamic modeling and kinetics. A simplified way is proposed to describe arc effects with the assumption that the plasma reactor is similar to a cascade of two plug flow reactors (PFR) as shown in figure 5 .

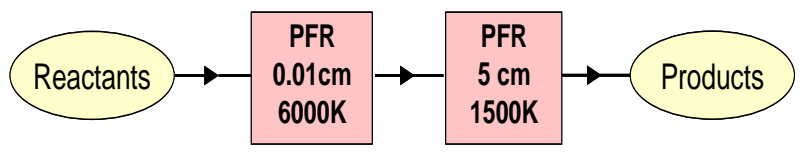

Figure 5. Schematic Plug Flow Reactor (PFR) model.

The first short length $(0.01 \mathrm{~cm})$ - high temperature PFR at $6000 \mathrm{~K}$ describes the gas mixture injection in the hot plasma zone at the upper electrode level. It is a PFR which use the conventional combustion kinetic mechanisms but does not take into account the electrons and the ions from the plasma. It is supposed to represent a thermal effect equivalent to the plasma effect. This PFR behaves as radical species injector in the surrounding reactive zone. The temperature of $6000 \mathrm{~K}$ is an estimation of the average temperature of the ionized channel. It is in the order of magnitude of the temperature measured on the axis of the discharge $(6500<\mathrm{T}(\mathrm{K})<7300)$ by molecular emission spectroscopy using $\mathrm{OH}, \mathrm{C}_{2}$, and $\mathrm{CN}$ bands.

The second $5 \mathrm{~cm}$ length - moderate temperature PFR at $1500 \mathrm{~K}$ describe the chemical reactions occurring in the reactive zone surrounding the plasma column. Various phenomena such as convection, diffusion, chemical dissociation and recombination occur in that zone. The temperature of $1500 \mathrm{~K}$ was obtained by software fitting in order to find equal concentrations of $\mathrm{CO}$ and $\mathrm{CO}_{2}$ in an inlet mixture with $10 \%$ mole fraction ethanol.

The mechanisms used in PFR $6000 \mathrm{~K}$ and $1500 \mathrm{~K}$ modeling is Gri 3.0 [12] taken from literature and the software used is Kintech Chemical Workbench [13]. For simulation dedicated to the methanol mixtures, only $\mathrm{O}, \mathrm{OH}, \mathrm{H}, \mathrm{H}_{2}, \mathrm{H}_{2} \mathrm{O}, \mathrm{CO}$ and $\mathrm{CO}_{2}$ concentrations are presented and considered for discussion. Results obtained from an inlet methanol mole fraction of $10 \%$ are plotted on figures 6 and 7 for PFR $6000 \mathrm{~K}$ and $1500 \mathrm{~K}$, respectively. The percentage (\%) corresponds to \% mole in vapor phase.

Simulated results of PFR at $6000 \mathrm{~K}$ (Figure 6) show that the reactive species (radicals), OH, H, O, can be produced and then injected in the PFR $1500 \mathrm{~K}$.

Composition along PFR length $1500 \mathrm{~K}$ is shown on figure 7. From this figure, an increase of the inlet flow corresponds to a decrease of the reactor length. Reduction in the effective length of the reactor leads to a decrease in the $\mathrm{H}_{2}$ and $\mathrm{CO}_{2}$ concentrations and an increase in $\mathrm{CO}$. Similar modeling is also applied for methanol inlet concentrations of 5, 15 and $20 \%$.

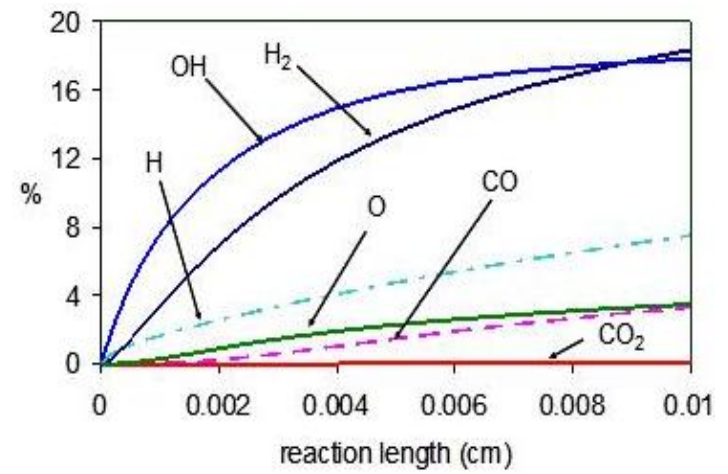

Figure 6. Species concentration as a function of reaction length: PFR $6000 \mathrm{~K}-10 \%$ methanol.

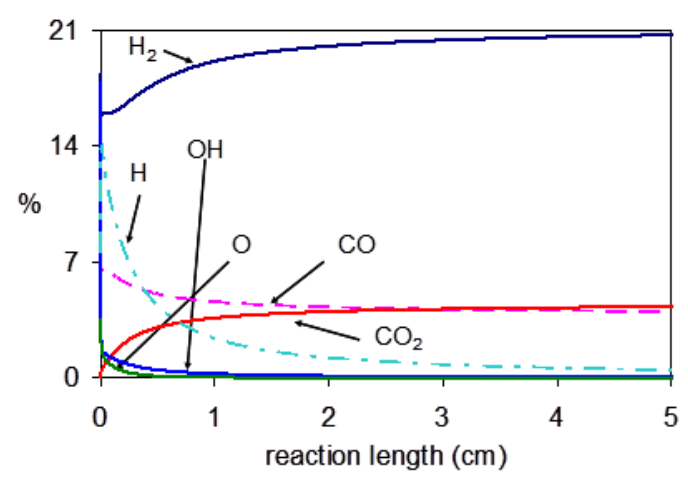

Figure 7. Species concentration as a function of reaction length: PFR $1500 \mathrm{~K}-10 \%$ methanol.

In figure 8 , comparisons between experimental results and modeling data concerning $\mathrm{H}_{2}$ concentrations $\mathrm{H}_{2} / \mathrm{CO}$, and $\mathrm{CO} / \mathrm{CO}_{2}$ are displayed for various inlet methanol concentrations. It is shown that the general trends in hydrogen production, carbon monoxide and carbon dioxide, are fairly 
well described by the model. It should be noted that the presence of the first PFR is essential because of the impossibility to find modeling results, compatible with the experiments, using only a single reactor PFR at $1500 \mathrm{~K}$. The best agreements between experimental and modeling results are obtained for $\mathrm{CO} / \mathrm{CO}_{2}$ ratios and $\mathrm{H}_{2}$ mole fractions. $\mathrm{H}_{2}$ mole fractions vary slowly. However, a maximum can be observed for a mole fraction of 0.15 . The results are not understood today but can be discussed with a parametric simulation. Such a work is underway.
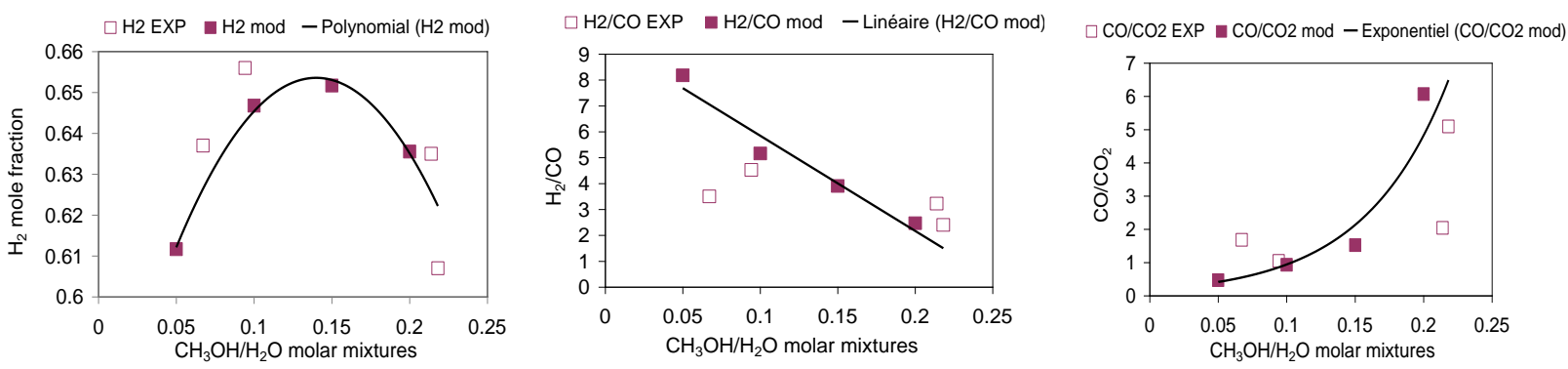

Figure 8. Comparison of model and experimental results.

\section{Low current plasma torch and biomass pyro-gasification}

\subsection{Plasma torch and biomass schematic view of the Pyroplasm arrangement}

Started at the end of 2006 and achieved in 2010, the Pyroplasm ANR French project had combined cyclone and a plasma reactor to quantitatively study the abatement efficiency of condensable vapours produced by biomass pyro-gasification [8]. The experimental set-up consists in a laboratory scaled continuous pilot plant [6-8]. It is composed of a biomass feeding section, a heated pyrolysis-cyclone reactor, a plasma reactor and the recovery of all the solids, liquids and gases. Thus, complete mass balances can be established. The plasma reactor can be placed at various locations between the pyrolysis reactor and the gas outlet. Figure 9 shows a schematic view of experimental set-up. Only comments about effects observed in A and B plasma setting are given in the paper.

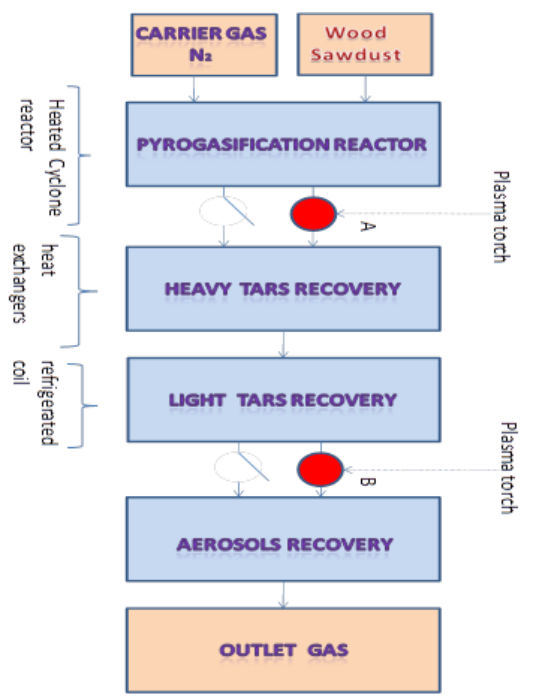

Figure 9. Schematic view of the experimental Pyroplasm set-up.

The raw biomass sawdust is prepared from wood pellets grind (mixture of oak and beech wood). A calibrated screw feeder (placed at the bottom of a stirred hopper) allows delivering a continuous and known mass flow rate in the rage $200-380 \mathrm{~g} \cdot \mathrm{h}^{-1}$, at the entrance of the reactor. Particles are 
transported from the end of the screw feeder to the top of the cyclone reactor by a nitrogen carrier gas controlled flow $\left(2-19 \times 10^{-4} \mathrm{~kg} \cdot \mathrm{s}^{-1}\right)$.

The pyro-gasification reactor is a cyclone reactor. The cyclone is made of refractory stainless steel and heated at its walls by induction. The wall temperature can be adjusted from 880 to $1220 \mathrm{~K}[1,8]$. Char is automatically separated from the gaseous products in a cylindrical collector placed at the bottom of the cyclone reactor. The fluid products include condensed vapours, aerosols and permanent gases. They first cross heat exchangers in order to recover a part of liquids called "Heavy tars". Then, a refrigerated coil is used to condense the residual vapours. The temperature at the exit of the refrigerated coil is regulated close to $258 \mathrm{~K}$. The tars recovered in the coil are called "Light tars". Finally, the aerosols are trapped in an electrostatic precipitator and a membrane filter placed in series. Ultimate vapours are trapped in a silica gel cartridge.

Clean gases are sampled and analysed by gas chromatography. The different concentrations of $\mathrm{H}_{2}$, $\mathrm{CO}, \mathrm{CO}_{2}, \mathrm{C}_{2}$ and $\mathrm{C}_{3}$ hydrocarbons are determined. Assuming a complete conversion of the biomass introduced in the reactor, the Mass Balance is given by the following expression and calculated from the outlet masses of char $\left(\mathrm{m}_{\text {char }}\right)$, tars $\left(\mathrm{m}_{\text {tars }}\right)$, gases $\left(\mathrm{m}_{\text {gases }}\right)$, ultimate vapors $\left(\mathrm{m}_{\mathrm{uv}}\right)$ and the inlet biomass $\left(\mathrm{m}_{\mathrm{bio}}\right)$ :

$$
\text { Mass Balance }=\frac{m_{\text {char }}+m_{\text {tars }}+m_{\text {gases }}+m_{u v}}{m_{\text {bio }}}
$$

\subsection{The plasma reactor}

The reactor, shown in figure 10, is a low current arc plasma torch. The plasma torch has a tip-cylinder configuration. It operates in a non-transferred mode. The inner electrode is a $1.5 \mathrm{~mm}$ diameter electrode located on the axis, while the nozzle electrode is a stainless steel cylinder with an axial internal passage. The reactants (i.e. carrier gas, condensable vapours and gases) are injected tangentially in a chamber located right in front of the inner electrode tip.

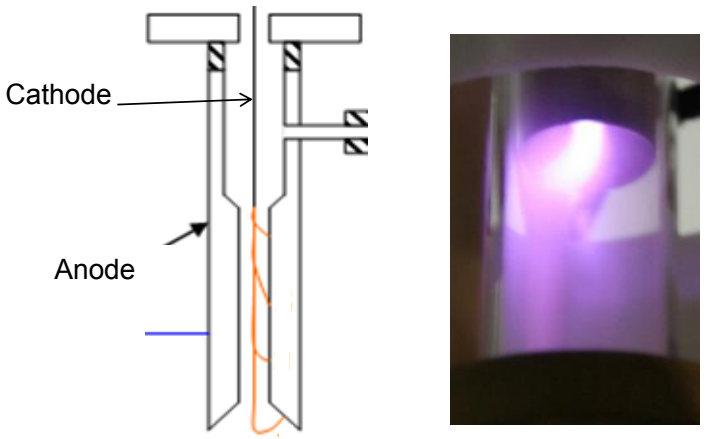

Figure 10. Schematic diagram and photography of low current plasma torch.

The plasma reactor is powered by means of two $50 \mathrm{~Hz}$ high voltage transformers $(230 \mathrm{~V} / 15 \mathrm{kV})$ with leakage flux which allows sinusoidal current waveforms with a constant RMS value of $155 \mathrm{~mA}$ (plasma power $50 \mathrm{~W}$ ) or 0.9 A (plasma power $160 \mathrm{~W}$ ). A scheme of the high voltage apparatus is displayed figure 11. Voltage is determined by arc properties in ionised gaseous mixture. Examples of voltage and current waveforms are given in figure 12 in case of $160 \mathrm{~W}$ power supply. 


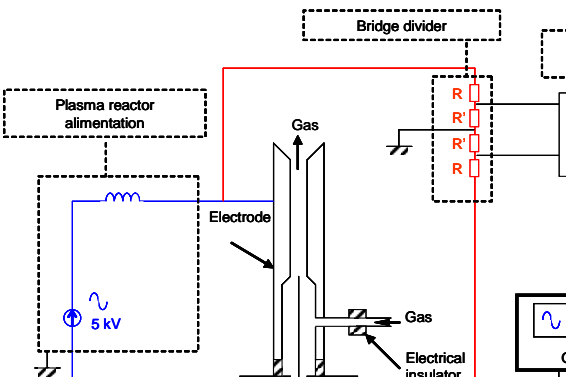

Figure 11. Functional scheme of the plasma torch and power supply.

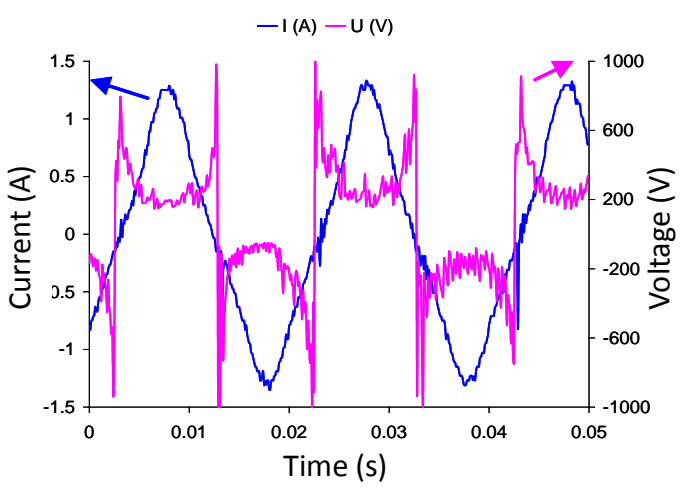

Figure 12. Voltage and current in plasma torch experiments (Average Power: 160W).

\subsection{Results and discussion}

Experiments are performed with the plasma reactor settled between the outlet of the cyclone reactor and the inlet of the three heat exchangers (A position in figure 9). The mass of all the products (solids, total liquids, permanent gases and ultimate vapours) during wood pyro-gasification at $1108 \mathrm{~K}$ is determined. Mass repartition of gases, liquids, solids and ultimate vapours are compared to a previous experiment realized without plasma reactor in which all the operating conditions are identical (cyclone walls temperature, carrier gas flow rate, biomass mass flow rate). Results have been previously published [7] and an example is shown in figure 13.

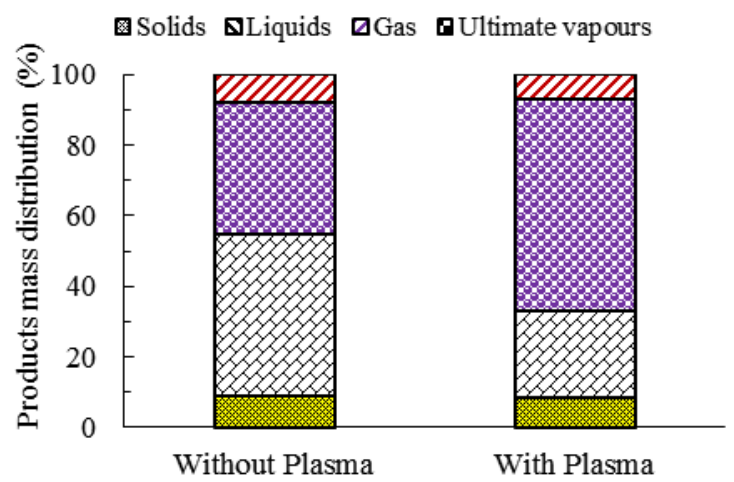

Figure 13. Influence of plasma on products masses distribution [7].

The plasma reactor has a strong influence on the liquid/gas distribution (figure 13). Indeed, the amount of produced permanent gas increases whereas the amount of total liquid decreases. Then, a non-negligible part of condensable vapours seems to be cracked by the plasma reactor, $45 \%$ of tars entering the plasma reactor are removed.

Typical composition gas mixtures obtained in case of pyro-gasification at wall temperature of the cyclone of about $1108 \mathrm{~K}$ (without plasma) is: $18 \% \mathrm{H}_{2}, 63 \% \mathrm{CO}, 12.5 \% \mathrm{CO}_{2}, 2.5 \% \mathrm{CH} 4$, and $1 \% \mathrm{C}_{2}-$ $\mathrm{C}_{3}$ species.

Experiments with the installation Pyroplasm showed that there is a slight increase of $\mathrm{H}_{2}$ production, from 18 to $20 \%$, and a decrease of CO production, from $63 \%$ to $61 \%$. Interesting results are also observed by setting plasma reactor at the outlet of the refrigerated coil used for light tars trapping (B position in figure 9). Experiments show that $70 \%$ of aerosols can be removed by the plasma.

\subsection{Short conclusion about Pyroplasm project}


The plasma reactor has a strong influence on the liquid/gas products distribution during wood flash pyro-gasification. Indeed, the amount of produced permanent gases increases whereas the amount of total liquid decreases. The aerosol is the fraction most easily destroyed. Destroyed tars generate gases containing more hydrogen than the pyrolysis gases.

The efficiency of a low current plasma torch is significant in the tar conversion process. However, for such a plasma torch, the physical and optical diagnostics are very difficult to perform. To better characterize main physical phenomena, additional studies are developed by using a simplified plasma reactor, called "Statarc" (described in the first part of this paper) and specially design for bio-oil steam reforming.

\section{Conclusion}

The results presented here show that the combination of plasma reactor with a pyro-gasification reactor is a promising way for a better use of biomass. It is also shown that oils derived from pyrolysis can be used to produce hydrogen rich syngas. The plasma methanol experiments show that the production of reactive species by low energy plasma can generate reactions over a significant volume in comparison to the volume of the plasma filament itself. This study justifies the development of new modeling including the combined effect of kinetic and aerodynamic models. It is shown that the plasma steam reforming of bio-oils generates a syngas with higher hydrogen concentrations compared to those obtained by pyro-gasification. This is due to the steam reforming reaction under the plasma effect.

The mass conversion yields of bio-oils, approximately $25 \%$, are however not sufficient to consider direct industrial applications by using these laboratory scale reactors. The design of new devices has to be performed for industrial scaling.

\section{Acknowledgments}

This work was supported by the French National Research Agency (ANR) under Pyroplasm project. The authors gratefully appreciate the technical assistance of G. Coudrat and R. Lainé from GREMI and LRGP laboratories, respectively.

\section{References}

[1] French Pyroplasm program 2006-2010 Pyrolyse de la biomasse à haute température assistée par plasma non thermique ANR PNRB

[2] Lédé J 2000 Industrial Engineering Chemistry Research 39 (4) 893

[3] Broust F, Ferrer M and Lédé J $200212^{\text {th }}$ European biomass conference for energy, industry and climate protection (Amsterdam The Netherlands) p 545

[4] Broust F 2003 PhD Thesis INPL-LSGC Nancy University (France).

[5] Ndiaye FT 2008 PhD Thesis INPL-LSGC Nancy University (France)

[6] Lédé J, Broust F, Ndiaye F T and Ferrer M 2007 Fuel 861800

[7] Han J and Kim H 2008 Renewable and Sustainable Energy Reviews 12397

[8] Falcoz Q, Leininger JP, Lédé J, Martin G, Luche J, Khacef A, Aubry O and Cormier J M 2009 $17^{\text {th }}$ conference and exhibition from research to industry and market (Hamburg Germany)

[9] Aubry O, Met C, Khacef A and Cormier J M 2005 Chemical Engineering Journal 106 p 241

[10] Petitpas G, Rollier J D, Darmon A, Gonzalez-Aguilar J, Metkemeijer R and Fulcheri L 2007 Int. J. of Hydrogen Energy 322848

[11] Rusu I and Cormier J M 2003 Chemical Engineering Journal 9123

[12] Smith G, Golden D M, Frenklach M, Moriarty N W, Eiteneer B, Goldenberg M, Bowman CT, Hanson R K, Song S, Gardiner Jr W C, Lissianski V and Qin Z http://www.me.berkeley.edu/gri-mech/

[13] Chemical Workbench (Kintech Lab.) http://www.kintechlab.com/ 